\title{
Pengaruh Rendahnya Intensitas Cahaya Terhadap Caulerpa racemosa (Forsskål) 1873 (Ulvophyceae:Caulerpaceae)
}

\author{
Elfonso Robby Sitorus*, Gunawan Widi Santosa, Rini Pramesti \\ Departemen IImu Kelautan, Fakultas Perikanan dan IImu Kelautan, Universitas Diponegoro \\ JI. Prof. H. Soedarto, S.H, Tembalang, Semarang, Jawa Tengah 50275, Indonesia \\ ${ }^{*}$ Corresponding author, e-mail: elfonsor@gmail.com
}

\begin{abstract}
ABSTRAK: Caulerpa racemosa merupakan spesies rumput laut hijau (Chlorophyta) yang hidup di daerah pasang surut maupun daerah yang bebas dari pasang surut. Permintaan pasar yang setiap tahun meningkat, sehingga dilakukan budidaya. Penelitian ini bertujuan untuk mengetahui pengaruh intensitas cahaya yang berbeda pada pertumbuhan $C$. racemosa. Penelitian ini menggunakan metode eksperimental laboratoris dan rancangan percobaan yang dipakai adalah Rancangan Acak Lengkap (RAL) yang terdiri dari 3 perlakuan dan 2 ulangan. Perlakuan pada penelitian ini dengan intensitas cahaya pada $A= \pm 1000$ lux; $B= \pm 500$ lux; $C= \pm 300$ lux. Pencapaian berat basah rata-rata sebagai berikut: $A= \pm 0,84$ gram ; $B= \pm 1,06$ gram ; $C= \pm 1,13$ gram. Laju Pertumbuhan Spesifik (SGR) $C$. racemosa adalah: $A=1,29 \pm 0,04 \%$ per hari ; $B=1,12 \pm 0,06 \%$ per hari ; $C=0,4 \pm 0,09 \%$ per hari. Hasil penelitian menunjukkan perlakuan intensitas cahaya yang berbeda berpengaruh sangat nyata terhadap berat dan laju pertumbuhan spesifik $C$. racemosa $(p<0,01)$.
\end{abstract}

Kata kunci : Pertumbuhan; C. Racemosa; Intensitas cahaya

\section{The Effect of Low Light Intensity of Caulerpa racemosa (Forsskål) 1873 (Ulvophyceae:Caulerpaceae)}

\begin{abstract}
Caulerpa racemosa is a species of green seaweed (Chlorophyta) that live in tidal areas and areas free from tides. The market demand of $C$. racemosa continues to increase, it is necessary to conduct cultivation for its production. The purpose of this research was to determine the effect of different light intensities on the growth of $C$. racemosa. This research used an experimental laboratory method and the experimental design used was a Completely Randomized Design (CRD) consisting of 3 treatments and 2 replications. The treatment in the research was by measuring the light intensity at $A= \pm 1000$ lux; $B= \pm 500$ lux; $C= \pm 300$ lux. The results showed that the average wet weight gained was : $A= \pm 0.84 \mathrm{gram} ; B= \pm 1.06 \mathrm{gram} ; C= \pm 1.13 \mathrm{grams}$. Specific growth rates of $C$. racemosa were: $A=1.29 \pm 0.04 \%$ per day ; $B=1.12 \pm 0.06 \%$ per day; $C=0.4 \pm 0.09 \%$ per day. The results of this study indicated that the treatment of different light intensities significantly affected the specific weight and grow rate of $C$. racemosa $(p<0.01)$.
\end{abstract}

Keywords : Growth; C. Racemosa; Light intensities

\section{PENDAHULUAN}

Indonesia merupakan negara maritim dengan panjang pantai yaitu $81.000 \mathrm{~km}$ dan memiliki sumberdaya hayati laut melimpah, salah satunya adalah rumput laut atau seaweed. Berdasarkan kandungan pigmennya, tumbuhan ini dibagi menjadi 3 kelas, yaitu rumput laut merah (Rhodophyceae), rumput laut hijau (Chlorophyceae), dan rumput laut coklat (Phaeophyceae) (Tjitrosoepomo, 2011).

C. racemosa termasuk dalam kelas rumput laut hijau yang dapat dikonsumsi dan memiliki berbagai manfaat untuk kesehatan. Masyarakat mengenal C. racemosa dengan Latoh, namun ketersediaannya lebih banyak megandalkan dari alam bukan dari budidaya (Ma'ruf et al., 2013). Kebutuhan pasar yang terus meningkat memaksa perlu adanya budidaya dengan berbagai faktor yang mempengaruhi pertumbuhannya dalam upaya peningkatan produksi (Zatnika, 2009). Intensitas cahaya merupakan salah satu faktor penting dalam metabolisme pertumbuhan dan proses fotosintesis (Indriani \& Sumiarsih, 1999). 
C. racemosa juga termasuk dalam Seaweed Feather, yang dapat dikonsumsi dan memiliki zat bioaktif seperti anti bakteri, anti oksidan, dan dapat digunakan untuk obat (Merdekawati et al., 2009). Tambahkan state of the art dari penelitian sebelumnya Berdasarkan penelitian sebelumnya, intensitas cahaya berpengaruh nyata $(p<0,01)$ terhadap pertumbuhan $C$. racemosa. Laju pertumbuhan spesifik tertinggi $(3,1 \%$ per hari) dilakukan dengan perlakuan \pm 3000 lux.

Tambahkan gap analisis Budidaya $C$. racemosa harus memperhatikan beberapa parameter seperti suhu, salinitas, dan intensitas cahaya. Intensitas cahaya merupakan faktor yang sangat berperan penting dalam metabolisme pertumbuhan dan proses fotosintesis (Pujihastuti, 2011). Menurut Prihatman (2000), sumber cahaya yang digunakan untuk melakukan penelitian lampu fluorescent sebesar \pm 1000 lux. Tujuan penelian ini untuk mengetahui pengaruh intensitas cahaya yang berbeda pada pertumbuhan $C$. racemosa serta mengetahui intensitas cahaya yang optimal pada pertumbuhan $C$. racemosa.

\section{MATERI DAN METODE}

Materi yang digunakan pada penelitian ini adalah $C$. racemosa yang berasal dari Balai Besar Pengembangan Budidaya Air Payau (BBPABAP), Jepara. Alat dan bahan yang digunakan seperti akuarium berukuran $50 \times 30 \times 35 \mathrm{~cm}$ sebagai wadah pemeliharaan, aerator sebagai pengikat oksigen, lampu TL 40 watt sebagai sumber cahaya, lux meter untuk mengukur intensitas cahaya dan beberapa alat untuk mengukur parameter kualitas perairan seperti refraktometer, kertas indikator $\mathrm{pH}$, termometer, timbangan digital, serta DO meter, air laut bersih, rumput laut $C$. racemosa, dan pupuk NPK.

Metode penelitian yang digunakan adalah metode eksperimental laboratoris. Metode ini bertujuan untuk mengetahui hubungan sebab akibat dari suatu manipulasi objek dengan kontrol (Swastawati et al., 2008). Metode dilakukan dengan cara memberi satu atau beberapa perlakuan yang dibandingkan dengan perlakuan lain untuk mengetahui hubungan sebab akibat dan dilakukan dalam skala laboratorium.

Rancangan percobaan yang digunakan adalah Rancangan Acak Lengkap (RAL) yang terdiri dari 3 perlakuan dan 2 ulangan. Rancangan penelitian ini dipilih karena lokasi penempatan wadah sampel dan berat awal dalam penelitian ini adalah homogen.

Langkah pertama untuk melakukan penelitian ini berupa persiapan wadah. Wadah berupa ember plastik untuk proses aklimatisasi rumput laut selama 3 hari untuk penyesuaian diri terhadap lingkungan baru. Persiapkan air laut yang akan dimasukkan ke dalam akuarium bervolume $10 \mathrm{~L}$ dan aerasi. Bibit $C$. racemosa yang telah diaklimatisasi, ditimbang, dan dipilih yang terbaik sebanyak $25 \mathrm{~g}$ setiap akuariumnya. Selanjutnya dimasukkan ke dalam akuarium yang telah terisi air laut dengan salinitas 35\% dan diberi perlakuan intensitas cahaya yang berbeda dengan wadah terbuka, dilapisi 1 kain kassa, dan 2 kain kassa untuk mengurangi intensitas cahaya.

Selama masa penelitian 42 hari dilakukan pengukuran parameter kualitas perairan. Pengukuran parameter kualitas perairan di media $C$. racemosa meliputi suhu, $\mathrm{pH}$ dan salinitas. Pengukuran ini akan dilakukan setiap 2 hari sekali dan salinitas akan disesuaikan bila sudah melebihi batas salinitas untuk hidup rumput laut yaitu 35 ppt.

Data yang diperoleh dalam penelitian ini meliputi berat basah, laju pertumbuhan spesifik (SGR), pengamatan visual C. racemosa, dan nilai kualitas air pada media pemeliharaan.Pengukuran berat basah dilakukan dengan meniriskan sampel $C$. racemosa sampai kadar air berkurang lalu ditimbang dengan timbangan digital.Laju pertumbuhan ini dihitung sebagai parameter utama pengaruh perlakuan berbeda terhadap kondisi rumput laut $C$. racemosa yang ditanam (Alamsjah et al., 2010).

\section{HASIL DAN PEMBAHASAN}

Berdasarkan penelitian yang dilakukan diperoleh data berupa pengukuran pertumbuhan $C$. racemosa (berat basah) dan laju pertumbuhan spesifik (SGR) Hasil penelitian ditampilkan dalam bentuk tabel dan grafik. Pencapaian berat basah $C$. racemosa selama 6 minggu ditunjukkan pada Tabel 1.

Berdasarkan hasil yang diperoleh, $C$. racemosa pada perlakuan $A$ dengan intensitas cahaya \pm 1000 lux tumbuh paling besar dengan berat basah mencapai $43,1 \mathrm{~g}$, sementara pada perlakuan 
C dengan intensitas cahaya \pm 300 lux tumbuh paling kecil dengan berat basah hanya mencapai 29,7 g. Laju pertumbuhan spesifik (SGR) C. racemosa selama 6 minggu pemeliharaan ditunjukkan pada Grafik 1.

Uji One Way ANOVA dan laju pertumbuhan spesifik $C$. racemosa menunjukkan $p<0,01$ artinya $\mathrm{HO}$ ditolak sehingga perlakuan yang diterapkan menyebabkan pertumbuhan pada $C$. racemosa berbeda sangat nyata. Hal ini bisa disimpulkan perbedaan intensitas cahaya berpengaruh terhadap pertumbuhan rumput $C$. racemosa seperti ditunjukkan. Hubungan perbedaan intensitas cahaya pada setiap media pemeliharaan terhadap laju pertumbuhan spesifik menunjukkan persamaan $y=-0,4436 x+1,8317$, dengan nilai koefisien korelasi $R^{2}=0,8867$. Koefisien korelasi menunjukkan adanya hubungan yang kuat antara perlakuan intensitas cahaya pada $C$. racemosa dengan laju pertumbuhan spesifik. Cahaya sangat berpengaruh pada proses fotosintesis karena cahaya dapat memacu aktivitas pembelahan sel, sehingga terjadi pelebaran dan perpanjangan pada bagan tubuh atau thalus yang pada akhirnya rumput laut mengalami pertumbuhan (Esteller et al., 2011).

Tabel 1. Berat Basah (g) C. racemosa pada Intensitas Cahaya yang Berbeda selama 6 Minggu

\begin{tabular}{|c|c|c|c|c|c|c|c|c|}
\hline \multirow{2}{*}{ Perlakuan } & & \multicolumn{7}{|c|}{ Minggu } \\
\hline & & 0 & 1 & 2 & 3 & 4 & 5 & 6 \\
\hline \multirow[b]{2}{*}{ rerata } & $A_{1}$ & 25 & 31,2 & 34,5 & 36,7 & 39,8 & 42,3 & 43,7 \\
\hline & $A_{2}$ & $\begin{array}{c}25 \\
25 \pm 0\end{array}$ & $\begin{array}{c}29,5 \\
30,35 \pm 1,20\end{array}$ & $\begin{array}{c}32,6 \\
33,05 \pm 1,34\end{array}$ & $\begin{array}{c}33,4 \\
35,05 \pm 2,33\end{array}$ & $\begin{array}{c}36,5 \\
38,15 \pm 2,33\end{array}$ & $\begin{array}{c}41,1 \\
41,7 \pm 0,84\end{array}$ & $\begin{array}{c}42,5 \\
43,1 \pm 0,84\end{array}$ \\
\hline \multirow{2}{*}{ B } & $B_{1}$ & 25 & 28,8 & 30,7 & 34,5 & 37,7 & 39,2 & 40,9 \\
\hline & $\mathrm{B}_{2}$ & 25 & 27,9 & 30,3 & 34,2 & 35,3 & 38,5 & 39,4 \\
\hline rerata & & $25 \pm 0$ & $28,35 \pm 0,63$ & $30,5 \pm 0,28$ & $34,35 \pm 0,21$ & $36,5 \pm 1,69$ & $38,85 \pm 0,49$ & $40,15 \pm 1,06$ \\
\hline \multirow{2}{*}{ C } & $\mathrm{C}_{1}$ & 25 & 26,2 & 26,4 & 27,1 & 27,5 & 27,6 & 28,9 \\
\hline & $\mathrm{C}_{2}$ & 25 & 27,1 & 27,5 & 28,7 & 28,9 & 29,4 & 30,5 \\
\hline rerata & & $25 \pm 0$ & $26,65 \pm 0,63$ & $26,95 \pm 0,77$ & $27,9 \pm 1,13$ & $28,2 \pm 0,98$ & $28,5 \pm 1,27$ & $29,7 \pm 1,13$ \\
\hline
\end{tabular}

Keterangan: $A=( \pm 1000$ lux $) ; B=( \pm 500$ lux $) ; C=( \pm 300$ lux $)$

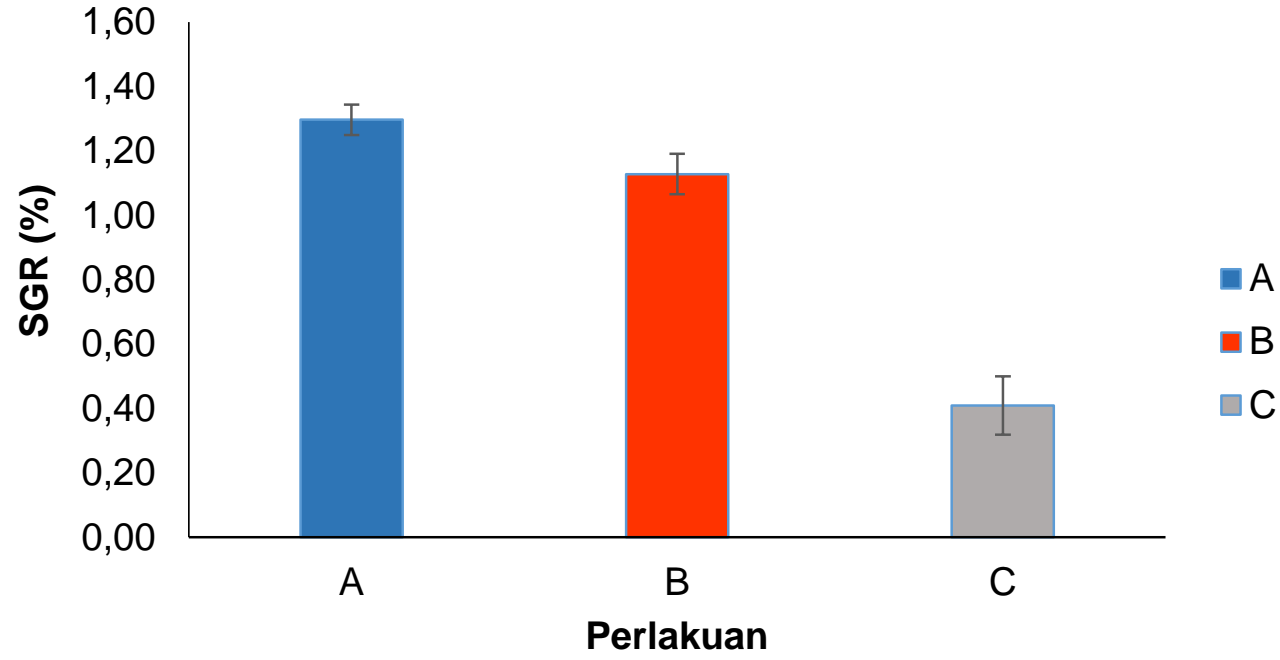

Gambar 1. Laju pertumbuhan spesifik (SGR) C. racemosa pada intensitas cahaya yang berbeda selama 6 minggu masa pemeliharaan. ( $A= \pm 1000$ lux; $B= \pm 500$ lux; $C= \pm 300$ lux $)$ 
Hendrajat (2010) mengungkapkan bahwa adanya kenaikan berat basah menunjukkan perkembangan rumput laut sudah memasuki tahap perpanjangan sel karena adanya nutrien yang cukup untuk pertumbuhan. Ketersediaan nutrien sangat mempengaruhi pertumbuhan rumput laut. Pernyataan tersebut sesuai dengan hasil dari penelitian ini yang mana pemberian nutrien dan cahaya menyebabkan rumput laut mengalami pertumbuhan yang signifikan. Berdasarkan hasil dan analisis data penelitian ini menujukkan bahwa $C$. racemosa menujukkan indikasi pertumbuhan setiap hari. Perbedaan intensitas cahaya memberikan efek pada nilai laju pertumbuhan spesifik yang berbeda sangat nyata $(p<0,01)$. Hal tersebut menujukkan bahwa cahaya memiliki peranan dalam pertumbuhan $C$. racemosa karena cahaya merupakan penyedia energi dalam keberlangsungan fotosintesis (Widodo \& Suadi, 2006).

Perbedaan intensitas cahaya pada tiap perlakuan yang diberikan kepada $C$. racemosa sangat mempengaruhi pertumbuhan masing - masing. Perlakuan A mendapat intensitas cahaya terbesar dengan \pm 1000 lux dan mengalami pertumbuhan paling besar dengan berat basah mencapat 43,1 g. Hal tersebut didukung oleh pernyataan Saptasari (2010), bahwa intensitas cahaya yang optimal untuk pertumbuhan rumput laut $C$. racemosa adalah \pm 2500 lux. Perlakuan $A$ mendapat intensitas cahaya yang paling besar dan paling mendekati dengan kondisi optimalnya. Sedangkan perlakuan $C$ hanya mendapat intensitas cahaya sebesar \pm 300 lux yang artinya mengalami pertumbuhan paling kecil dengan 29,7 g.

Perlakuan A ( \pm 1000 lux) menghasilkan laju pertumbuhan yang lebih baik $(1,29 \pm 0,04 \%$ berat/hari) dibandingkan dengan perlakuan $B(1,12 \pm 0,06 \%$ berat/hari) dan perlakuan $C(0,4 \pm$ $0,09 \%$ per hari) karena cahaya yang diterima pada perlakuan A lebih besar dibandingkan dengan perlakuan B dan C. Hal ini diduga pada konsentrasi tersebut faktor lingkungan terutama intensitas cahaya yang dibutuhkan $C$. racemosa untuk pertumbuhan lebih mendekati kondisi di alam. Intensitas cahaya merupakan faktor pembatas pada proses fotosintesis, makin besar intensitas cahaya maka proses fotosintesis dapat berjalan semakin cepat pula dan pada akhirnya akan meningkatkan berat basah rumput laut (Susilowato et al., 2019).

Perlakuan B dan C memberikan respon intensitas cahaya terhadap laju pertumbuhan spesifik yang lebih rendah dibandingkan perlakuan A karena cahaya yang didapatkan tidak lebih baik untuk memenuhi kebutuhan pertumbuhan. Setiap perlakuan menggunakan lampu TL dengan daya 40 watt sebagai sumber cahaya yang diletakkan di atas permukaan media pemeliharan. Lampu TL yang digunakan sebagai sumber cahaya menghasilkan intensitas cahaya yang lebih besar dengan daya yang lebih rendah memiliki suhu yang lebih rendah dibandingkan dengan lampu pijar, serta cahaya putih yang dihasilkan mampu menyediakan cahaya untuk fotosintesis tumbuhan (Budiyani et al., 2012).

\section{KESIMPULAN}

Berdasarkan hasil penelitian dapat disimpulkan bahwa rumput laut Caulerpa racemosa tumbuh pada semua perlakuan cahaya yang dilakukan. Semakin tinggi intensitas cahaya dalam kondisi penelitian ini, semakin cepat pula pertumbuhan. Perlakuan cahaya yang berbeda mempengaruhi pertumbuhan (berat basah dan nilai laju pertumbuhan) rumput laut $C$. racemosa $(p<0,01)$.

\section{DAFTAR PUSTAKA}

Alamsjah, M.A., Nurines O.A. \& Sri S. 2010. Pengaruh Lama Penyinaran Terhadap Pertumbuhan dan Klorofil a Gracillaria verrucosa pada sistem budidaya indoor. Jurnal IImiah Perikanan dan Kelautan, 2(1):21-29.

Budiyani, F.C., Suwartimah, K. \& Sunaryo. 2012. Pengaruh Penambahan Nitrogen dengan Konsentrasi yang Berbeda terhadap Laju Pertumbuhan Rumput Laut Caulerpa racemosa var uvivera. Journal of Marine Research, 1(1):10-18.

Esteller, J.B., Guirao, L.M, Gill, J.M \& Ruiz. 2011. Photosynthesis and daily metabolic carbon balance of the invasive Caulerpa racemosa var. Cylindracea (Chlorophyta: Caulerpales) along a depth gradient. Scientia Marina, 75(4):803-810 
Hendrajat, A.E. 2010. Polikultur Udang Vaname (Litopenaeus vannamei) dan Rumput Laut (Gracilaria verrucosa). Balai Riset Perikanan Budidaya Air Payau, Sulawesi.

Indriani, H \& Sumiarsih, E. 1999. Budidaya, Pengolahan dan Pemasaran Rumput Laut.Jakarta: Penebar Swadaya.

Ma'ruf, Widodo F., Ibrahim, R., Dewi, E.N., Susanto, E \& Amalia, U. 2013. Profil Rumput Laut Caulerpa racemosa dan Gracillaria verrucosa sebagai Edible Food. Jurnal Saintek Perikanan, $9(1): 68-74$.

Merdekawati, W. \& Susanto, A.B. 2009. Kandungan dan Komposisi Pigmen Rumput Laut serta Potensinya untuk Kesehatan. Squalen, 4 (2):41-47

Prihatman, K. 2000. Manipulasi Cahaya untuk Merangsang Pertumbuhan Tanaman Air. Kantor Deputi Menegristek Bidang Pendayagunaan dan Pemasyarakatan IImu Pengetahuan dan Teknologi (BAPPENAS). Jakarta. $13 \mathrm{hlm}$.

Pujihastuti, Y. P. 2011. Nitrification and Denitrification in Pond. Jurnal Akuakultur Indonesia, 10(1) : 6.

Suparmi, \& Sahri, A. 2009. Mengenal Potensi Rumput Laut: Kajian Pemanfaatan Sumberdaya Rumput Laut dari Aspek Industri dan Kesehatan. Majalah IImiah Sultan Agung, 44(118):95116.

Susilowati, A., Mulyawan, A.E., Yaqin, K., Rahim, S.W., \& Jabbar, F.B. 2019. Effects of vermicompost on growth performance and antioxidant status of seaweed Caulerpa racemosa, South Sulawesi, Indonesia. Aquaculture, Aquarium, Conservation \& Legislation, 12(4):11421148

Swastawati. F., Wijayanti, I \& Susanto, E. 2008. Pemanfaatan Limbah Kulit Udang Menjadi Edible Coating untuk Mengurangi Pencemaran Lingkungan. Jurnal Perikanan dan IImu Kelautan, 4(4):101-106.

Tjitrosoepomo, G. 2011. Taksonomi Tumbuhan Schizophyta, Thallophyta, Bryophyta, Pteridophyta. Gajah Mada University. Yogyakarta.

Widodo, J., \& Suadi. 2006. Pengelolaan Sumber Daya Perikanan Laut. Gadjah Mada Universitas Press. Yogyakarta.

Zatnika, A. 2009. Pedoman Teknis Budidaya Rumput Laut. Badan Pengkajian dan Penerapan Teknologi. Jakarta. 